\title{
Targeted next-generation sequencing of cancer genes in poorly differentiated thyroid cancer
}

\author{
Tiemo S Gerber', Arno Schad ${ }^{2}$, Nils Hartmann², Erik Springer ${ }^{2}$, Ulrich Zechner ${ }^{3}$ and Thomas J Musholt ${ }^{1}$ \\ ${ }^{1}$ Endocrine Surgery Section, Department of General, Visceral and Transplantation Surgery, University Medicine, Mainz, Germany \\ ${ }^{2}$ Department of Pathology, University Medicine, Mainz, Germany \\ ${ }^{3}$ Institute of Human Genetics, University Medicine, Mainz, Germany \\ Correspondence should be addressed to T S Gerber: tiemogerber@gmail.com
}

\begin{abstract}
Poorly differentiated thyroid carcinoma (PDTC) is a rare malignancy with higher mortality than well-differentiated thyroid carcinoma. The histological diagnosis can be difficult as well as the therapy. Improved diagnosis and new targeted therapies require knowledge of DNA sequence changes in cancer-relevant genes. The TruSeq Amplicon Cancer Panel was used to screen cancer genomes from 25 PDTC patients for somatic single-nucleotide variants in 48 genes known to represent mutational hotspots. A total of 4490 variants were found in 23 tissue samples of PDTC. Ninety-eight percent (4392) of these variants did not meet the inclusion criteria, while 98 potentially pathogenic or pathogenic variants remained after filtering. These variants were distributed over 33 genes and were all present in a heterozygous state. Five tissue samples harboured not a single variant. Predominantly, variants in $P 53$ (43\% of tissue samples) were identified, while less frequently, variants in APC, ERBB4, FLT3, KIT, SMAD4 and BRAF (each in $17 \%$ of tissue samples) as well as ATM, EGFR and FBXW7 (each in 13\% of tissue samples) were observed. This study identified new potential genetic targets for further research in PDTC. Of particular interest are four observed ERBB4 (alias HER4) variants, which have not been connected to this type of thyroid carcinoma so far. In addition, APC and SMAD4 mutations have not been reported in this subtype of cancer either. In contrast to other reports, we did not find CTNNB1 variants.
\end{abstract} \author{
Key Words \\ thyroid \\ - endocrine cancers \\ - rare diseases/syndromes
}

Endocrine Connections (2018) 7, 47-55

\section{Introduction}

Poorly differentiated thyroid carcinoma (PDTC) represents an aggressive variant of thyroid cancer that predominantly arises from the differentiated variants of papillary and follicular thyroid carcinoma (PTC and FTC, respectively) but occasionally from normal follicular cells $(1,2)$. The incidence varies between $2-3 \%$ and $15 \%$, depending on geographical location (3). The Turin consensus, which is based on histological growth pattern, nuclear features, mitosis, necrosis and convoluted nuclei, offered an algorithm to diagnose this entity (4). However, even with this consensus paper published in 2007, PDTC still represents a challenging diagnosis for pathologists and clinicians. Molecular changes in PDTC are heterogeneous. No exclusive mutation has been identified that could potentially facilitate the differentiation process $(5,6,7)$. The advanced cancer stage and the impaired or complete lack of radioactive iodine uptake drive the search for effective therapeutic alternatives such as targeted therapies. Although Landa and coworkers (1) as well as $\mathrm{Xu}$ and Ghossein (8) reported an extensive investigation on PDTC, we still need to learn more about the driving molecular alterations.

Using a next-generation sequencing (NGS) approach, we screened 23 PDTC for variants in 48 cancer-relevant

$$
\begin{array}{lr}
\text { http://www.endocrineconnections.org } & \text { ( } 2018 \text { The authors } \\
\text { https://doi.org/10.1530/EC-17-0290 } & \text { Published by Bioscientifica Ltd }
\end{array}
$$

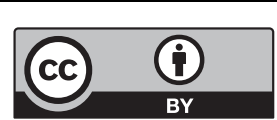


genes. The main goal addressed in this exploratory study was to characterise novel genetic changes as potential targets for further research as well as establishing the NGS technique in our laboratory.

\section{Materials and methods}

\section{Patients and tissue acquisition}

Patients treated in the Department of General, Visceral und Transplantation Surgery at University Medical Centre, Mainz, Germany between 2007 and 2015 were included in the study. The study was approved by Ethics Committee of the medical association of Rheinland Pfalz. Consent has been obtained from each patient or subject after full explanation of the purpose and nature of all procedures used. Archival tissue from the patients was retrieved and reviewed using the Turin consensus algorithm, in the course of which necrosis, the number of mitotic cells per ten high-powered fields (mitotic index) and the extrathyroidal and vascular invasion were determined. The samples were also immunohistochemically stained for thyroglobulin, thyroid transcription factor-1 and Ki-67. We did not analyse matched pairs of individual tumour-normal tissue, but only PDTC itself. Each histological slide was diagnosed by an experienced pathologist. Questionable samples were not included in this study. Twenty-five of 32 reviewed patients fulfilled all criteria to diagnose a PDTC. Furthermore, we assessed if the samples also fulfilled the Memorial Sloan-Kettering Cancer Center (MSKCC) criteria for PDTC as proposed by Hiltzik and coworkers (9). These were defined by the presence of $\geq 5$ mitotic cells per ten high-powered fields and/or fresh tumour necrosis. The fraction of malignant cells in tumour tissue was determined by visual estimation of the percentage of malignant cells (tumour cell to nontumour cell). An overview of the patient data is presented in Table 1. Routine Sanger sequencing was performed on the BRAF V600E and BRAF wild-type V600 gene locus.

\section{DNA extraction and sample quality control}

Genomic DNA was extracted from the formalin-fixed and paraffin-embedded tumour material. To reduce contamination, microscope slides of the tumour stained with haematoxylin-eosin were used to select areas for macrodissection. The selected material was scratched off from $2 \mu \mathrm{m}$ thick unstained slides. It was deparaffinised with xylene and ethanol and digested by proteinase $\mathrm{K}$ in lysis buffer overnight at $56^{\circ} \mathrm{C}$. The samples were purified with MPC Protein Precipitation Solution (Biozym Scientific GmbH, Oldendorf, Germany) and precipitated with isopropanol. The DNA was quantified using a spectrophotometer to measure the absorbance at $260 \mathrm{~nm}$. The DNA quality was tested with the FFPE QC Kit for the TruSeqAmplicon Cancer Panel (Illumina, San Diego, CA, USA) using the manufacturer's instructions. Table 2 for a full list of covered genes. Two samples failed the quality control criteria, resulting in 23 analysed PDTCs.

\section{Library preparation and MiSeq sequencing}

Sequencing libraries were prepared using the TruSeq Amplicon Cancer Panel (Illumina) with the MiSeq Reagent Kit, v2 according to the manufacturer's instructions. The MiSeq System (Illumina) was used to launch the massively parallel sequencing process to capture the exons of 48 genes with 212 amplicons.

\section{Data analysis}

Using the TruSeq Amplicon Workflow on the MiSeq Reporter, the data were demultiplexed and aligned to the human reference genome hg19. The output was generated in the variant caller format. BaseSpace Variant Studio, v2.2.4 (Illumina) was used for post processing. This programme could integrate information about called variants from the Cosmic (v65) and ClinVar (v05.09.2013) scientific databases. The application uses the Variant Effect Predictor (VEP) tool for Annotation and Analysis of coding sequence changes. VEP also harnesses algorithms such as Polymorphism Phenotyping 2 (PolyPhen-2) and Sorting Intolerant From Tolerant (SIFT).

To eliminate false positive called variants we used a specific algorithm. First, all variants needed at least a coverage above 20 , a sequencing depth of at least 100 and a mutation frequency of $10 \%$, resulting in a threshold of 10 counts for a variant. Second, all variants needed to be nonsynonymous and to have a genotype quality of at least 30. Third, all variants needed to be marked as potentially deleterious in SIFT, as potentially damaging in PolyPhen, as potentially pathogenic or pathogenic in ClinVar or listed in Cosmic. Genes were named in accordance with the guidelines for human gene nomenclature (Supplementary Table 1 , see section on supplementary data given at the end of this article; (10)).

$$
\begin{aligned}
& \text { http://www.endocrineconnections.org } \\
& \text { https://doi.org/10.1530/EC-17-0290 }
\end{aligned}
$$

(c) 2018 The authors Published by Bioscientifica Ltd

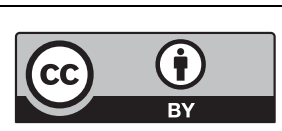

This work is licensed under a Creative Commons Attribution 4.0 International License. 


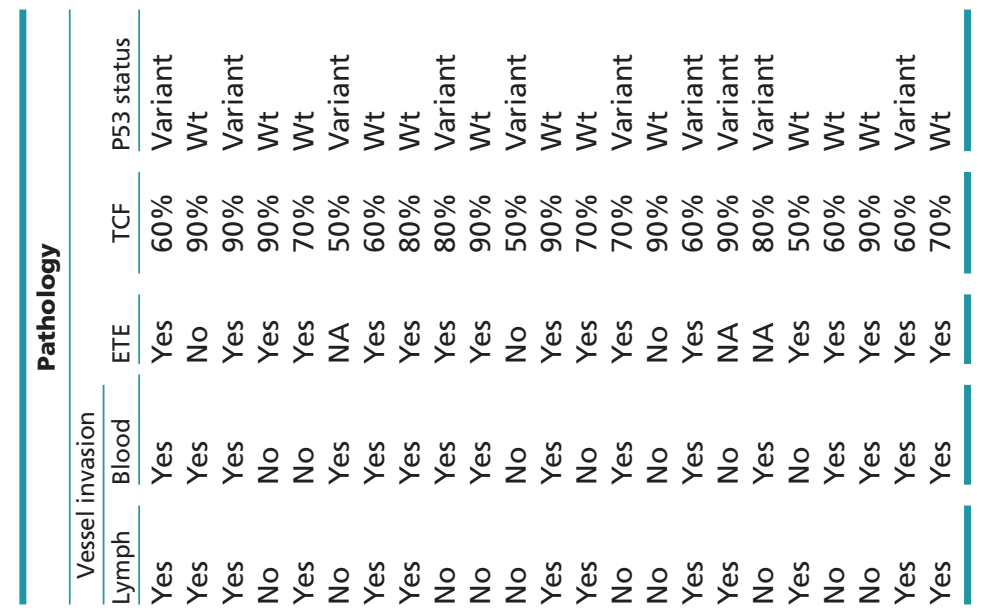

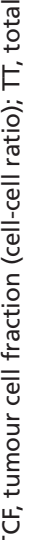

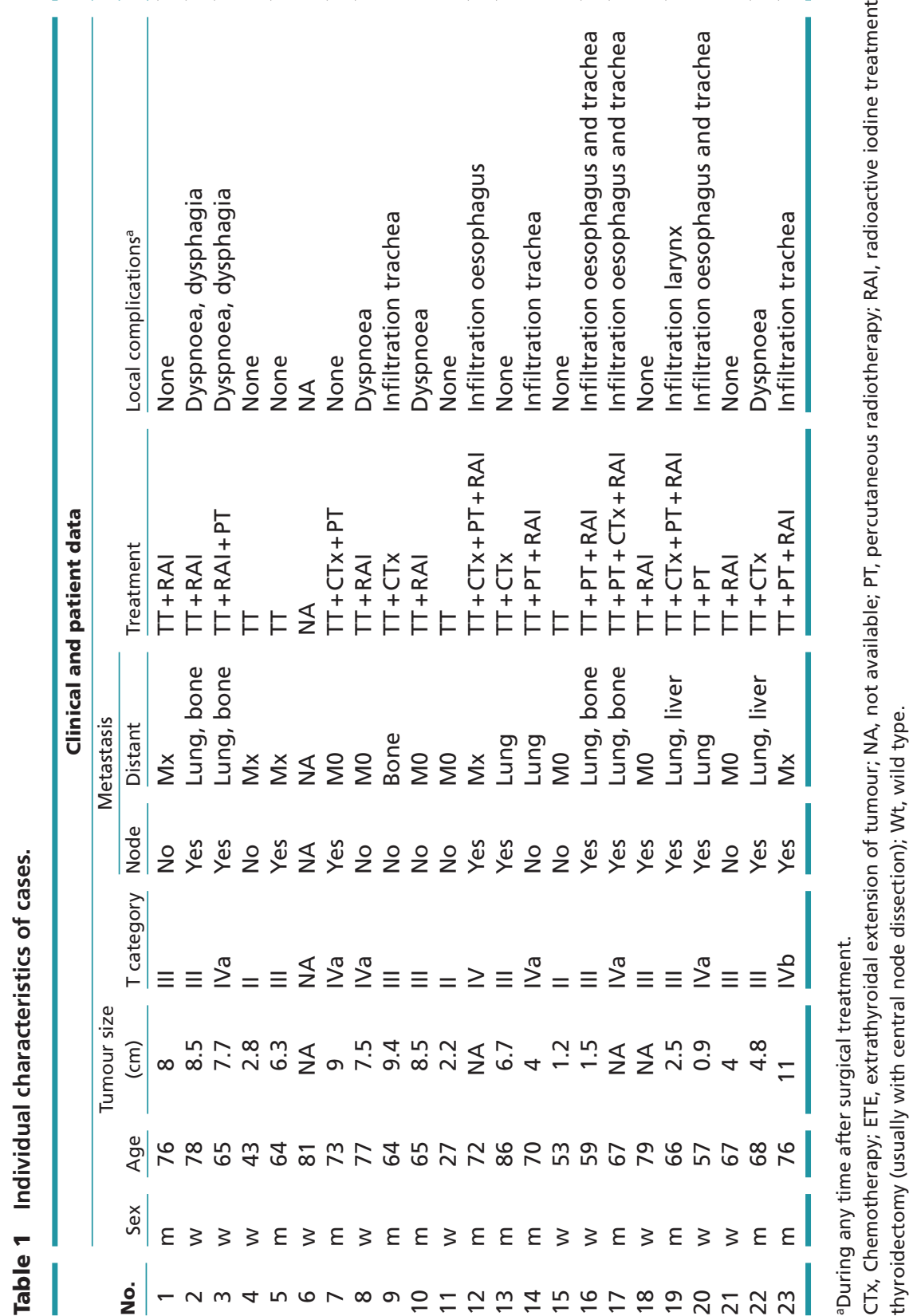


Table 2 Truseq amplicon cancer panel gene list.

\begin{tabular}{llll}
\hline Illumina TSCAP & & & \\
\hline ABL1 & ERBB4 & JAK2 & PIK3CA \\
AKT1 & FBXW7 & JAK3 & PTEN \\
ALK & FGFR1 & KDR & PTPN11 \\
APC & FGFR2 & KIT & RB1 \\
ATM & FGFR3 & KRAS & RET \\
BRAF & FLT3 & MET & SMAD4 \\
CDH1 & GNA11 & MLH1 & SMARCB1 \\
CDKN2A & GNAQ & MPL & SMO \\
CSF1R & GNAS & NOTCH1 & SRC \\
CTNNB1 & HNF1A & NPM1 & STK11 \\
EGFR & HRAS & NRAS & TP53 \\
ERBB2 & IDH1 & PDGFRA & VHL \\
\hline
\end{tabular}

\section{Results}

Eighteen tissue samples of PDTCs showed a total number of 98 variants as presented in Fig. 1. All variants were present in a heterozygous state. Ninety-eight genetic changes were single-nucleotide variants (90 missense variants, two nonsense variants, and 6 splice site variants), while one was a deletion leading to a frameshift. The sequencing depth ranged between 101 and 10258 (median 161). The mutation frequency had a median of 13.2. The coverage varied between 21 and 280 with a median of 102. Eightyseven variants were identified with a genotype quality of 100. For detailed information on genetic alterations see Supplementary Table 1.

The most commonly altered gene was TP53, affected in 10 of 23 samples (43\%). All TP53 variants occurred at different base positions. The FLT3, SMAD4 and BRAF variants were detected in each of four samples. Four variants were observed in the each of the $A P C, B R A F$, ERBB4, FLT3, KIT and SMAD4 gene loci. In three of the four samples with $B R A F$ variants, we found the p.V600E variant and in one, the p.G469V variant. Changes in the ATM, EGFR and FBXW7 genes were identified in each of the three samples (13\%).

One-hundred percent concordance in BRAF variant status was observed between NGS and routine conventional Sanger sequencing. Each tumour sample of PDTC diagnosed with the Turin consensus criteria was also classified as PDTC by the MSKCC-criteria that indicated more aggressive PDTC.

\section{Discussion}

Two main questions drive the search for new molecular alterations of PDTC. First, what targeted therapies could add a promising approach to the treatment? Second, which mutational markers could improve the accuracy of diagnosis for advanced thyroid carcinomas? This study aims to contribute to this growing area of research by exploring 48 genes of interest. It is beyond the scope of this explorative study to prove causality or to address the progression from well-differentiated thyroid carcinoma (WDTC) to PDTC.

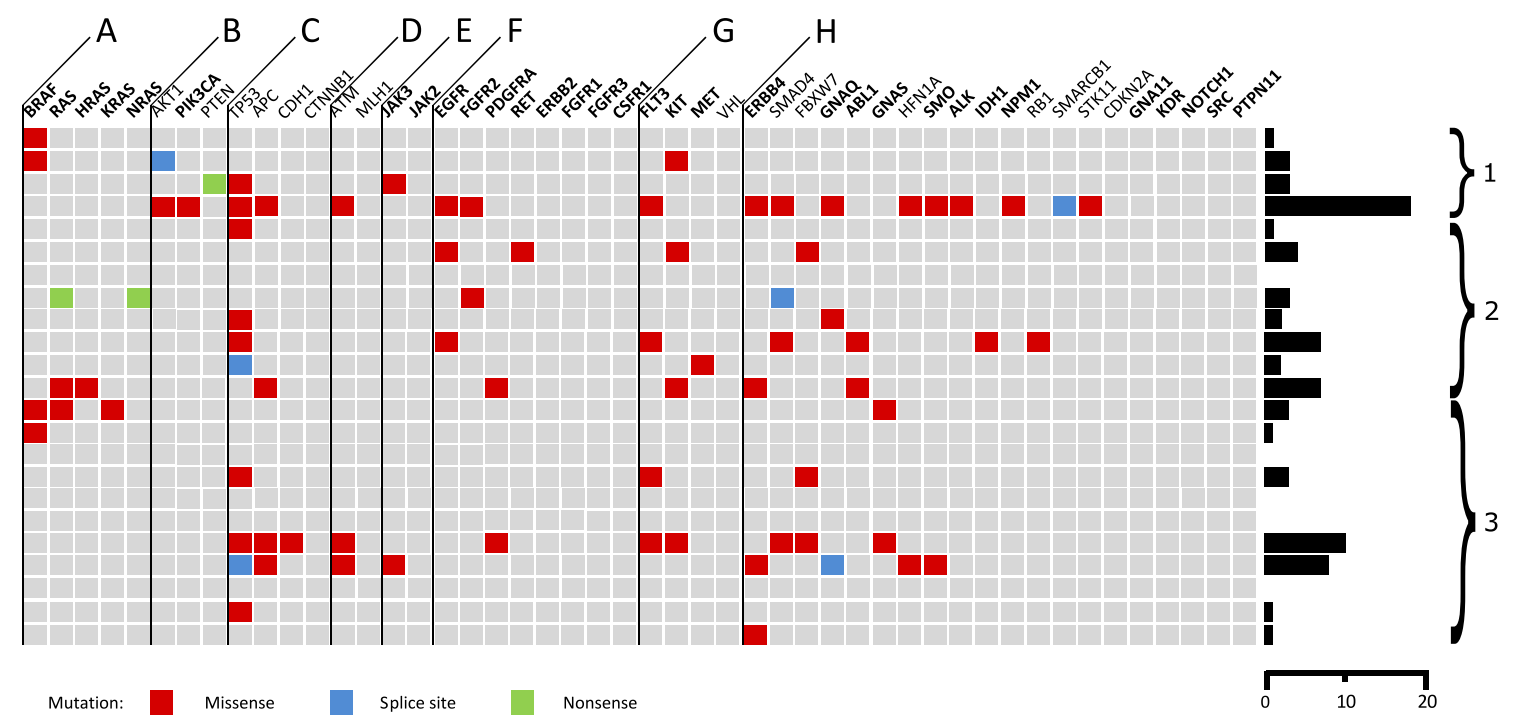

Figure 1 The columns show the analysed genes sorted by the molecular pathway affected. Oncogenes are displayed bold while tumor suppressor genes are displayed normal. (A) RAS, (B) PIK3, (C) Wnt, (D) DNA damage control, (E) STAT, (F) RAS + PIK3, (G) RAS + PIK3 + STAT, (H) others. The rows show the 23 PDTC specimens. The variant effect is shown by the colour of the mutation. On the right side of the figure is indicated the mutational burden. (1) PDTC with coexisting PTC. (2) PDTC with coexisting follicular tumour components. (3) PDTC only.

$$
\begin{array}{lr}
\text { http://www.endocrineconnections.org } & \text { ○ } 2018 \text { The authors } \\
\text { https://doi.org/10.1530/EC-17-0290 } & \text { Published by Bioscientifica Ltd }
\end{array}
$$

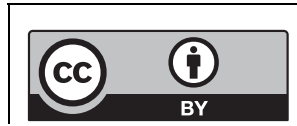

This work is licensed under a Creative Commons Attribution 4.0 International License. 


\section{BRAF, TP53, RAS}

While tumour-initiating somatic mutations leading to papillary thyroid carcinoma have been researched to a great extent, it remains uncertain whether and to what extent particular genetic alterations participate in the tumour progression to PDTC. The Cancer Genome Atlas Research Network study has identified many oncogenic mutations for PTC. It is generally agreed today that PDTC can originate from WDTC (11).

Landa and coworkers has shown that the changes to the $B R A F$ to $R A S$ relationship are still preserved in PDTC (1). For these reasons, one could assume that certain driver mutations are conserved during the dedifferentiation process. In our study, we found three RAS variants (one each of $N-, K$ - and $H R A S$ ) and three BRAF p.V600E variants. However, it is not the same as a $B R A F / R A S$-score based on mRNA data (11). In accordance with the aforementioned studies, there have been no RAS and BRAF p.V600E variants in the same tissue sample.

Mutations in BRAF, EIF1AX, TP53 and TERT are associated with aggressive behaviour of thyroid malignancies $(2,8,12)$. BRAF and TP53 are associated with the dedifferentiation progress to anaplastic thyroid carcinomas (ATCs) (13). In our study, there were 10/23 cases of PDTC harbouring a p53 variant. There was no significant difference regarding the clinical course, extrathyroidal extension or vascular invasion between TP53-positive tumours and the other tumours. One possible reason may be the preselection of an already aggressive subtype of cancer. Some previously published works have assessed TP53 mutations in PDTC. They observed lower rates $(8,27$ and 38\%) of this variant than in our series $(1,14,15)$. The variety might be related to the generally low number of patients in our study (23 tissue samples) as well as in compared series (84, 22 and 46 patients). The TERT and EIF1AX gene locations were not included in the applied cancer panel.

In contrast to previous studies, we found less RAS variants (13\%) than described in the literature $(20-55 \%)(16,17,18,19,20)$. These numbers are slightly lower than the value we expected. It seems plausible that a number of limitations could have influenced the obtained results. On the one hand, we used tissue that was formalin fixed and paraffin embedded for several years, which leads to the necessity of a very conservative filtering process to avoid false-positive findings from artefacts. This implies that there could be true-positive variants that have been lost in the background of artefacts. On the other hand, it is obvious that the overall small number of PDTC cases impairs conclusions based on the comparison of percentages.

\section{APC, ATM, CTNNB1, EGFR and ERBB4}

PDTC are a genetically heterogeneous entity. In this study, we identified new potential genetic targets for further investigation. Two of these are EGFR (ERBB1) and ERBB4, which have not been previously reported to play a role in thyroid carcinogenesis. ERBB1 is known to be mutated in cancers like gliomas or small-cell lung cancer and associated with the epithelial-mesenchymal transition as well as tumour invasion (21). In colon cancer, the mutation of ERBB4 resulted in a loss of differentiation and an activation of the phosphoinositide 3-kinase (PI3K) signalling pathway (22).

Another valuable target is $A P C$. Recent studies on PTC identified $A P C$ as well as $A T M$ as potential driver mutations (11). PDTC may harbour mutations that are present in PTC as they may derive from WDTC (23). Furthermore, APC mutations have been observed in ATC (24). Considering these arguments, it seems possible that this mutation plays a role in PDTC carcinogenesis as well.

Somatic mutations of CTNNB1 were discussed being associated PDTC and ATC (25). However, we detected no variants of this gene in the PDTC examined. The absence of CTNNB1 mutations supports the hypothesis of Rocha and coworkers (26) that loss of E-cadherin expression rather than $\beta$-catenin (CTNNB1) gene mutations induces the process of tumour dedifferentiation.

\section{SMAD4 and KIT}

SMAD4 encodes a mediator protein in the transforming growth factor $\beta$ (TGF- $\beta$ ) signalling pathway. This can lead to a loss of TGF- $\beta$-mediated growth inhibition (27). In our study, five variants affected four patients (17\%). The observed mutations were scattered along the sequence of the SMAD4 gene locus, suggesting that there is no mutational hotspot present. This locus is known to be altered in WDTC, oesophageal adenocarcinoma, pancreatic cancer and colorectal cancer $(27,28,29)$. A SMAD4 immunohistochemistry expression study has shown a correlation with poor survival in colon cancer (30). An in-depth examination of SMAD4 status demonstrated that abnormalities in this locus occur in benign as well as in malignant thyroid tumours $(15 / 56,27 \%)$, which was interpreted by the authors as indicative of an early event in thyroid tumorigenesis (28). All this leads to the assumption 


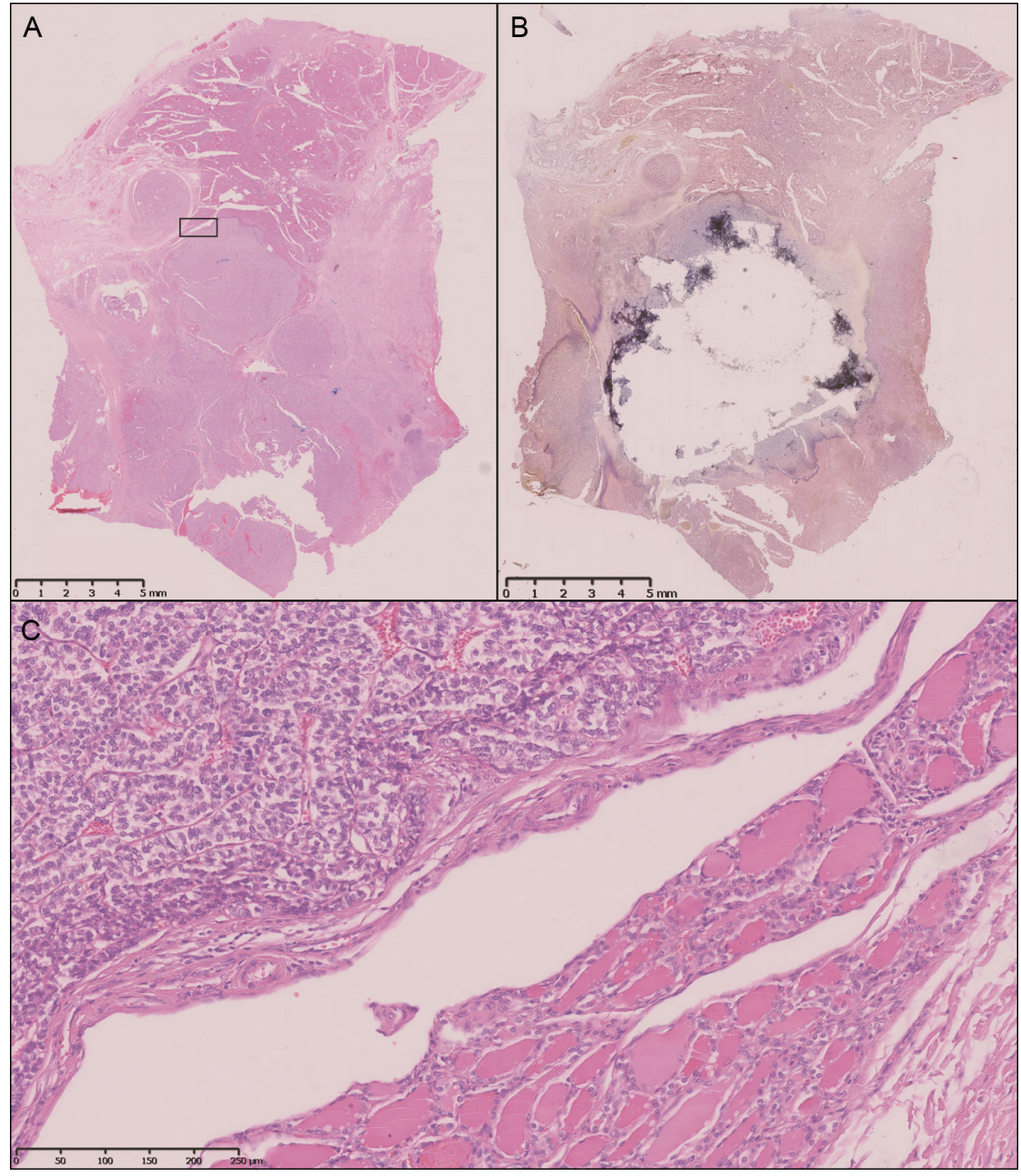

\section{Figure 2}

Macrodissection of a tumour with two different entities. Complete slide of the specimen before (A) and after (B) dissection of the PDTC

(C) A solid growing PDTC is demonstrated on the upper left next to a coexisting follicular thyroid tumour. Magnified clipping of a as indicated. ( $A, B$ and $C$ : hematoxylin-eosin stain; $A$ and $B: 5 \times$ magnification; C: $200 \times$ magnification). that the presence of SMAD4 mutations cannot differentiate between well-differentiated thyroid cancer and PDTC.

KIT encodes for a tyrosine kinase receptor and mediates growth regulation. Mutations in this gene are associated with haematologic diseases and gastrointestinal stromal tumours (31). KIT expression is reduced in PTC compared to benign nodules (32). Its assessment can improve the diagnosis in fine-needle aspiration $(33,34)$. There are, however, little data available for KIT mutational status in PDTC, although it is known that alterations in KIT transcripts increase with tumour progression from WDTC to PDTC $(35,36)$. In a study with 118 ATCs, none showed a KIT mutation (37). In our study, we detected four KIT variants. This discrepancy may indicate a slowing effect on cancer growth that is lost during tumour dedifferentiation to anaplastic thyroid cancer, which may be lost in favour of a more deleterious mutation in the downstream signalling pathways.

\section{Coexistent follicular or papillary tumours}

Surprisingly, we found many tumours with coexistent follicular or papillary carcinoma components (Figs 1 and 2). Eight PDTCs showed follicular coexistent components while five showed proportions with papillary carcinomas. Given the higher incidence of PTC than FTC, this could indicate a more frequent progression of FTC to PDTC. This is in accordance with the findings of Soares and coworkers (38) who emphasised that PDTC are more closely related to FTC than to PTC. The authors established their assumption on the absence of $B R A F$ variants in 19 PDTC. In contrast to their results, we found three BRAF V600E variants. Two of the three p.V600E BRAF variants were in PDTC with PTC proportions. The discrepancy is most likely related to the fact that Soares and coworkers excluded PDTC with PTC components in their series. 


\section{Methodological considerations}

Five PDTCs did not show any genetic alteration at all, which implies that yet unknown driving genetic alterations exist or that the applied methods failed to detect them. According to Bozic and coworkers (39), the actual selective growth advantage of a cancer by typical mutations is much smaller than commonly assumed. The majority of genes leading to a carcinoma (or supporting its dedifferentiation consecutively) have a low mutation frequency (40). Thus, it is possible that either these PDTCs had genetic variants not covered by the NGS panel or they had a mutation frequency less than $10 \%$ and were not distinguishable from artefacts.

The results of the present study demonstrate that there are many noteworthy genes that could be responsible for the dedifferentiation of thyroid carcinoma, but a number of restrictions of our study should be mentioned. One should note that we did not analyse blood or normal tissue to discriminate between true mutations or SNP. In a detailed examination of germline mutations in tumour tissue $3 \%$ of all samples showed germline mutations (41). We can assume similar results. Given the exploratory nature of this study, the variants presented here can only serve as an indicator for more targeted studies that should consider pathogenic germline alterations.

Furthermore, it is important to emphasise that the data have not been completely validated by Sanger sequencing. Acknowledging the limitations of validation of NGSderived variants using Sanger sequencing, we can surmise that the validation rate is precise enough for an exploratory study (42). Admittedly, contrary to the aforementioned study, we used paraffin-embedded formalin-fixed tissue. This pre-treated tissue could potentially be the source of sequencing artefacts. Following recommendations to reduce this effect, we macrodissected tumour-rich tissue, measured the quantity of DNA and excluded insufficient tissue samples (43). Given the nature of the TruSeq Amplicon Cancer Panel, we only sequenced exonic DNA with a limitation on certain genes. Due to this limitation, it was not possible to detect rearrangements of oncogenes like RET and NTRK1 or mutations of TERT. The latter are suspected to be connected to the disease progression of WDTC and to distinguish PDTCs from ATCs (1). However, rearrangements are rarely described in PDTC possibly because WDTC expressing RET/PTC hybrid oncogenes will usually not dedifferentiate further (44).

Even with the recent progress in the knowledge of molecular changes in PDTC, we think that our study reveals some novel variants, possibly influencing future research.

\section{Supplementary data}

This is linked to the online version of the paper at https://doi.org/10.1530/ EC-17-0290.

\section{Declaration of interest}

The authors declare that there is no conflict of interest that could be perceived as prejudicing the impartiality of the research reported.

\section{Funding}

This research did not receive any specific grant from any funding agency in the public, commercial or not-for-profit sector.

\section{Acknowledgements}

This publication contains data from the dissertation of T S Gerber. This data was reported at the Joint Meeting of the CAEK and the BAETS 2016 as an abstract of no more than 300 words.

\section{References}

1 Landa I, Ibrahimpasic T, Boucai L, Sinha R, Knauf JA, Shah RH, Dogan S, Ricarte-Filho JC, Krishnamoorthy GP, Xu B, et al. Genomic and transcriptomic hallmarks of poorly differentiated and anaplastic thyroid cancers. Journal of Clinical Investigation 2016126 1052-1066. (https://doi.org/10.1172/JCI85271)

2 Musholt TJ \& Musholt PB. Molecular genetic markers for thyroid FNAB. Established assays and future perspective. Nuklearmedizin Nuclear Medicine 201554 94-100.

3 Sanders EM Jr, LiVolsi VA, Brierley J, Shin J \& Randolph GW. An evidence-based review of poorly differentiated thyroid cancer. World Journal of Surgery 200731 934-945. (https://doi.org/10.1007/s00268007-9033-3)

4 Volante M, Collini P, Nikiforov YE, Sakamoto A, Kakudo K, Katoh R, Lloyd RV, LiVolsi VA, Papotti M, Sobrinho-Simoes M, et al. Poorly differentiated thyroid carcinoma: the Turin proposal for the use of uniform diagnostic criteria and an algorithmic diagnostic approach. American Journal of Surgical Pathology 200731 1256-1264. (https://doi.org/10.1097/PAS.0b013e3180309e6a)

5 Volante M \& Papotti M. Poorly differentiated thyroid carcinoma: 5 years after the 2004 WHO classification of endocrine tumours. Endocrine Pathology 201021 1-6. (https://doi.org/10.1007/s12022009-9100-4)

6 Nambiar A, Pv S, Susheelan V \& Kuriakose MA. The concepts in poorly differentiated carcinoma of the thyroid: a review article. Journal of Surgical Oncology 2011103 818-821. (https://doi. org/10.1002/jso.21803)

7 Schmid KW \& Fuhrer D. The role of molecular pathology in thyroid cancer. Tumor diagnostics, cytology and targeted therapy. Onkologe 201521 584. (https://doi.org/10.1007/s00761-014-2858-0)

$8 \mathrm{Xu}$ B \& Ghossein R. Genomic landscape of poorly differentiated and anaplastic thyroid carcinoma. Endocrine Pathology 201627 205-212. (https://doi.org/10.1007/s12022-016-9445-4)

9 Hiltzik D, Carlson DL, Tuttle RM, Chuai S, Ishill N, Shaha A, Shah JP, Singh B \& Ghossein RA. Poorly differentiated thyroid carcinomas defined on the basis of mitosis and necrosis: a clinicopathologic study of 58 patients. Cancer 2006106 1286-1295. (https://doi. org/10.1002/cncr.21739)

10 Wain HM, Bruford EA, Lovering RC, Lush MJ, Wright MW \& Povey S. Guidelines for human gene nomenclature. Genomics 200279 464-470. (https://doi.org/10.1006/geno.2002.6748) http://www.endocrineconnections.org https://doi.org/10.1530/EC-17-0290
○ 2018 The authors Published by Bioscientifica Ltd
This work is licensed under a Creative Commons Attribution 4.0 International License. 
11 Cancer Genome Atlas Research Network. Integrated genomic characterization of papillary thyroid carcinoma. Cell 2014159 676-690. (https://doi.org/10.1016/j.cell.2014.09.050)

12 Lee SE, Hwang TS, Choi YL, Han HS, Kim WS, Jang MH, Kim SK \& Yang JH. Prognostic significance of TERT promoter mutations in papillary thyroid carcinomas in a BRAF(V600E) mutation-prevalent population. Thyroid 201626 901-910. (https://doi.org/10.1089/ thy.2015.0488)

13 McFadden DG, Vernon A, Santiago PM, Martinez-McFaline R, Bhutkar A, Crowley DM, McMahon M, Sadow PM \& Jacks T. p53 constrains progression to anaplastic thyroid carcinoma in a Brafmutant mouse model of papillary thyroid cancer. PNAS $2014 \mathbf{1 1 1}$ E1600-E1609. (https://doi.org/10.1073/pnas.1404357111)

14 Pita JM, Figueiredo IF, Moura MM, Leite V \& Cavaco BM. Cell cycle deregulation and TP53 and RAS mutations are major events in poorly differentiated and undifferentiated thyroid carcinomas. Journal of Clinical Endocrinology and Metabolism 201499 E497-E507. (https://doi.org/10.1210/jc.2013-1512)

15 Takeuchi Y, Daa T, Kashima K, Yokoyama S, Nakayama I \& Noguchi S. Mutations of p53 in thyroid carcinoma with an insular component. Thyroid 19999 377-381. (https://doi.org/10.1089/thy.1999.9.377)

16 Nikiforova MN, Wald AI, Roy S, Durso MB \& Nikiforov YE. Targeted next-generation sequencing panel (ThyroSeq) for detection of mutations in thyroid cancer. Journal of Clinical Endocrinology and Metabolism 201398 E1852-E1860. (https://doi.org/10.1210/jc.20132292)

17 Volante M, Rapa I, Gandhi M, Bussolati G, Giachino D, Papotti M \& Nikiforov YE. RAS mutations are the predominant molecular alteration in poorly differentiated thyroid carcinomas and bear prognostic impact. Journal of Clinical Endocrinology and Metabolism 200994 4735-4741. (https://doi.org/10.1210/jc.2009-1233)

18 Garcia-Rostan G, Zhao H, Camp RL, Pollan M, Herrero A, Pardo J, Wu R, Carcangiu ML, Costa J \& Tallini G. ras mutations are associated with aggressive tumor phenotypes and poor prognosis in thyroid cancer. Journal of Clinical Oncology 200321 3226-3235. (https://doi.org/10.1200/JCO.2003.10.130)

19 Basolo F, Pisaturo F, Pollina LE, Fontanini G, Elisei R, Molinaro E, Iacconi P, Miccoli P \& Pacini F. N-ras mutation in poorly differentiated thyroid carcinomas: correlation with bone metastases and inverse correlation to thyroglobulin expression. Thyroid $2000 \mathbf{1 0}$ 19-23. (https://doi.org/10.1089/thy.2000.10.19)

20 Pilotti S, Collini P, Mariani L, Placucci M, Bongarzone I, Vigneri P, Cipriani S, Falcetta F, Miceli R, Pierotti MA, et al. Insular carcinoma: a distinct de novo entity among follicular carcinomas of the thyroid gland. American Journal of Surgical Pathology 199721 1466-1473. (https://doi.org/10.1097/00000478-199712000-00009)

21 Appert-Collin A, Hubert P, Cremel G \& Bennasroune A. Role of ErbB receptors in cancer cell migration and invasion. Frontiers in Pharmacology 20156 283. (https://doi.org/10.3389/ fphar.2015.00283)

22 Williams CS, Bernard JK, Demory Beckler M, Almohazey D, Washington MK, Smith JJ \& Frey MR. ERBB4 is over-expressed in human colon cancer and enhances cellular transformation. Carcinogenesis 201536 710-718. (https://doi.org/10.1093/carcin/ bgv049)

23 Nakazawa T, Celestino R, Machado JC, Cameselle-Teijeiro JM, Vinagre J, Eloy C, Benserai F, Lameche S, Soares P \& SobrinhoSimoes M. Cribriform-morular variant of papillary thyroid carcinoma displaying poorly differentiated features. International Journal of Surgical Pathology 201321 379-389. (https://doi. org/10.1177/1066896912473355)

24 Kurihara T, Ikeda S, Ishizaki Y, Fujimori M, Tokumoto N, Hirata Y, Ozaki S, Okajima M, Sugino K \& Asahara T. Immunohistochemical and sequencing analyses of the Wnt signaling components in Japanese anaplastic thyroid cancers. Thyroid 200414 1020-1029. (https://doi.org/10.1089/thy.2004.14.1020)
25 Soares P, Lima J, Preto A, Castro P, Vinagre J, Celestino R, Couto JP, Prazeres H, Eloy C, Maximo V, et al. Genetic alterations in poorly differentiated and undifferentiated thyroid carcinomas. Current Genomics 201112 609-617. (https://doi. org/10.2174/138920211798120853)

26 Rocha AS, Soares P, Fonseca E, Cameselle-Teijeiro J, Oliveira MC \& Sobrinho-Simoes M. E-cadherin loss rather than beta-catenin alterations is a common feature of poorly differentiated thyroid carcinomas. Histopathology 200342 580-587. (https://doi. org/10.1046/j.1365-2559.2003.01642.x)

27 Zhou S, Buckhaults P, Zawel L, Bunz F, Riggins G, Dai JL, Kern SE, Kinzler KW \& Vogelstein B. Targeted deletion of Smad4 shows it is required for transforming growth factor beta and activin signaling in colorectal cancer cells. PNAS 199895 2412-2416. (https://doi. org/10.1073/pnas.95.5.2412)

28 Lazzereschi D, Nardi F, Turco A, Ottini L, D'Amico C, MarianiCostantini R, Gulino A \& Coppa A. A complex pattern of mutations and abnormal splicing of Smad4 is present in thyroid tumours. Oncogene 200524 5344-5354. (https://doi.org/10.1038/ sj.onc.1208603)

29 van Nistelrooij AM, van Marion R, Koppert LB, Biermann K, Spaander MC, Tilanus HW, van Lanschot JJ, Wijnhoven BP \& Dinjens WN. Molecular clonality analysis of esophageal adenocarcinoma by multiregion sequencing of tumor samples. BMC Research Notes 201710 144. (https://doi.org/10.1186/s13104-0172456-5)

30 Yan P, Klingbiel D, Saridaki Z, Ceppa P, Curto M, McKee TA, Roth A, Tejpar S, Delorenzi M, Bosman FT, et al. Reduced expression of SMAD4 is associated with poor survival in colon cancer. Clinical Cancer Research 201622 3037-3047. (https://doi.org/10.1158/10780432.CCR-15-0939)

31 Cruse G, Metcalfe DD \& Olivera A. Functional deregulation of KIT: link to mast cell proliferative. Immunology and Allergy Clinics of North America 201434 219-237. (https://doi.org/10.1016/j. iac.2014.01.002)

32 Tomei S, Mazzanti C, Marchetti I, Rossi L, Zavaglia K, Lessi F, Apollo A, Aretini P, Di Coscio G \& Bevilacqua G. c-KIT receptor expression is strictly associated with the biological behaviour of thyroid nodules. Journal of Translational Medicine 2012107. (https://doi.org/10.1186/1479-5876-10-7)

33 Grim JE. Fbxw7 hotspot mutations and human colon cancer: mechanistic insights from new mouse models. Gut 201463 707-709. (https://doi.org/10.1136/gutjnl-2013-305144)

34 Welcker M \& Clurman BE. FBW7 ubiquitin ligase: a tumour suppressor at the crossroads of cell division, growth and differentiation. Nature Reviews Cancer 20088 83-93. (https://doi. org/10.1038/nrc2290)

35 Balamurugan K, Sharan S, Klarmann KD, Zhang Y, Coppola V, Summers GH, Roger T, Morrison DK, Keller JR \& Sterneck E. FBXW7alpha attenuates inflammatory signalling by downregulating C/EBPdelta and its target gene Tlr4. Nature Communications 20134 1662. (https://doi.org/10.1038/ncomms2677)

36 Mlecnik B, Bindea G, Kirilovsky A, Angell HK, Obenauf AC, Tosolini M, Church SE, Maby P, Vasaturo A, Angelova M, et al. The tumor microenvironment and Immunoscore are critical determinants of dissemination to distant metastasis. Science Translational Medicine 20168 327ra326. (https://doi.org/10.1126/ scitranslmed.aad635)

37 Tiedje V, Ting S, Herold T, Synoracki S, Latteyer S, Moeller LC, Zwanziger D, Stuschke M, Fuehrer D \& Schmid KW. NGS based identification of mutational hotspots for targeted therapy in anaplastic thyroid carcinoma. Oncotarget 20178 42613-42620. (https://doi.org/10.18632/oncotarget.17300)

38 Soares P, Trovisco V, Rocha AS, Feijao T, Rebocho AP, Fonseca E, Vieira de Castro I, Cameselle-Teijeiro J, Cardoso-Oliveira M \& SobrinhoSimoes M. BRAF mutations typical of papillary thyroid carcinoma

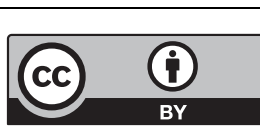

This work is licensed under a Creative Commons Attribution 4.0 International License. 
are more frequently detected in undifferentiated than in insular and insular-like poorly differentiated carcinomas. Virchows Archiv 2004 444 572-576. (https://doi.org/10.1007/s00428-004-1018-0)

39 Bozic I, Antal T, Ohtsuki H, Carter H, Kim D, Chen S, Karchin R, Kinzler KW, Vogelstein B \& Nowak MA. Accumulation of driver and passenger mutations during tumor progression. PNAS 2010107 18545-18550. (https://doi.org/10.1073/pnas.1010978107)

40 Nehrt NL, Peterson TA, Park D \& Kann MG. Domain landscapes of somatic mutations in cancer. BMC Genomics 201213 (Supplement 4) S9. (https://doi.org/10.1186/1471-2164-13-S4-S9)

41 Jones S, Anagnostou V, Lytle K, Parpart-Li S, Nesselbush M, Riley DR, Shukla M, Chesnick B, Kadan M, Papp E, et al. Personalized genomic analyses for cancer mutation discovery and interpretation. Science
Translational Medicine 20157 283ra253. (https://doi.org/10.1126/ scitranslmed.aaa7161)

42 Beck TF, Mullikin JC \& Biesecker LG. Systematic evaluation of sanger validation of NextGen sequencing variants. Clinical Chemistry 2016 62 647-654. (https://doi.org/10.1373/clinchem.2015.24962)

43 Do H \& Dobrovic A. Sequence artifacts in DNA from formalinfixed tissues: causes and strategies for minimization. Clinical Chemistry 201561 64-71. (https://doi.org/10.1373/ clinchem.2014.223040)

44 Eloy C, Ferreira L, Salgado C, Soares P \& Sobrinho-Simoes M. Poorly differentiated and undifferentiated thyroid carcinomas. Turk Patoloji Dergisi 2015 (Supplement 31) 1 48-59. (https://doi.org/10.5146/ tjpath.2015.01314)

Received in final form $\mathbf{5}$ November 2017

Accepted 13 November 2017

Accepted Preprint published online 13 November 2017 http://www.endocrineconnections.org https://doi.org/10.1530/EC-17-0290
() 2018 The authors Published by Bioscientifica Ltd

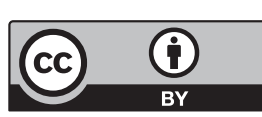

This work is licensed under a Creative Commons Attribution 4.0 International License. 